\title{
ÁREAS MONETÁRIAS ÓTIMAS: DESENVOLVIMENTOS RECENTES E PERSPECTIVAS PARA OS PAÍSES DO MERCOSUL
}

\author{
Daniel Arruda Coronel ${ }^{1}$ \\ Airton Lopes Amorim² \\ Antônio Carvalho Campos ${ }^{3}$
}

\section{Resumo}

Este artigo realizou uma revisão das contribuições mais importantes da teoria das Áreas Monetárias Ótimas (AMO) e verificou, à luz dessas contribuições, quais as perspectivas para a implantação de tal política no Mercosul. Os paradigmas em torno da criação de uma Área Monetária Ótima (AMO), assim como seus principais resultados, foram analisados por meio das referências teórico-empíricas do processo de implantação da moeda única da Europa. Nesse contexto, fez-se uma rápida exposição da coordenação macroeconômica em blocos regionais, procurando apontar as contribuições que esse tipo de coordenação vem acarretar ao processo de integração econômica Os resultados do trabalho indicam os principais custos e benefícios de uma AMO no Mercosul, além de apontar os principais obstáculos para implementar políticas monetárias macroeconômicas em países em desenvolvimento.

Palavras-chave: Área Monetária Ótima; Coordenação Política; Mercosul.

JEL Classification: F02; F33; F59

Doutorando em Economia Aplicada Economia Aplicada pela Universidade Federal de Viçosa (UFV), Mestre em Agronegócios pela Universidade Federal do Rio Grande do Sul e Bolsista de Doutorado do Conselho Nacional de Desenvolvimento Científico e Tecnológico (CNPq). E-mail: daniel.coronel@ufv.br

2 Doutorando em Economia Aplicada e Mestre em Economia UFV e Bolsista de Doutorado do CNPq. E-mail: aimorim2007@yahoo.com.br

3 Professor Titular do Programa de Pós-Graduação em Economia Aplicada e Bolsista de Produtividade nível I do CNPq. E-mail: acampos@ufv.br 


\section{INTROCUÇÃO}

Os paradigmas em torno da criação de uma Área Monetária Ótima (AMO) estão fortemente fundamentados pelas referências teórico-empíricas do processo de implantação da moeda única da Europa. Ao analisar essas concepções, este artigo traz à luz do processo europeu os pressupostos para criar uma AMO no Mercosul.

Nessa perspectiva, visualizam-se as principais concepções sobre coordenação de políticas macroeconômicas e seus efeitos no processo de decisões governamentais, bem como as contribuições que podem ser extraídas dessa coordenação para o processo de integração econômica em blocos regionais.

Ao revisar a literatura sobre Área Monetária Ótima, duas questões, relacionadas principalmente com implementação dessa política econômica, merecem destaque, a saber: quais as etapas para implementação de uma Área Monetária Ótima e quais os principais custos e benefícios de implementação de tal política macroeconômica.

O objetivo deste trabalho foi rever as contribuições mais importantes da Teoria das Áreas Monetárias Ótimas (AMO), destacando, assim, seus pressupostos fundamentais, possibilitando apontar os custos e benefícios de uma AMO no Mercosul, além de indicar as principais dificuldades de implementar tal política macroeconômica. Como objetivo complementar, procura-se entender o processo de unificação monetária, para fins de coordenação macroeconômica, em processos de integração econômica. Para isso, utilizou-se o método dedutivo com base no arcabouço bibliográfico de políticas e experiências de AMO, visando encontrar elementos na literatura e em processos já consolidados, como a União Européia.

Este trabalho está estruturado da seguinte maneira: além desta introdução, na seção 2, fazem-se algumas considerações sobre o debate das áreas monetárias na literatura econômica. Na seção 3, apresentam-se as evidências empíricas sobre áreas monetárias ótimas, com algumas considerações sobre a possibilidade de uma AMO nos países do MERCOSUL; e, por fim, são apresentadas as principais conclusões do trabalho. 


\section{O DEBATE SOBRE ÁREAS MONETÁRIAS ÓTIMAS NA LI- TERATURA ECONÔMICA}

\subsection{A fase inicial}

Políticas globalmente equilibradas e estáveis são pré-requisitos para o desempenho bem-sucedido de qualquer sistema monetário internacional, no qual os países atuam no mercado mundial sob um conjunto de acordos monetários e cambiais que compõem o Sistema Monetário Internacional.

Desde 1870, os países estiveram sujeitos a diferentes sistemas monetários. Mesmo diante de diferentes sistemas, era nítida a necessidade de uma coordenação entre as políticas macroeconômicas adotadas pelos países, caso contrário, a exemplo do período entre guerras, ocorreria a adoção de políticas do tipo "empobreça seus vizinhos".

A partir da década de 1990, observou-se, em nível mundial, maior abertura das economias ao comércio internacional. Além dos benefícios que gerou a cada país em particular, essa abertura tornou as economias mais interdependentes, resultando na maior necessidade de coordenação das políticas macroeconômicas dos países. A revitalização dos processos de integração, no início da década de 1990, principalmente nas regiões em desenvolvimento, foi um exemplo disto, pois os países buscavam, em conjunto, uma resposta para a crise da década de 1980.

$\mathrm{Na}$ Teoria da Integração Econômica consta que o processo de integração entre países dá-se por fases distintas, quais sejam, Área de Livre Comércio, União Aduaneira, Mercado Comum, União Econômica e Integração Econômica Total. Da fase inicial à final, os países vão evoluindo quanto à quebra de barreiras e coordenação de suas políticas, sendo, atualmente, a União Européia a expressão maior de uma integração econômica total.

A razão básica para a busca de mecanismos de coordenação macroeconômica entre as economias deve-se ao grau de interdependência destas, ou seja, ao fato de que as ações de uma economia podem afetar outra (DUTRA 2003, p.149).

Em um cenário de políticas macroeconômicas com fundamentação cambial e monetária, a base da teoria das Áreas Monetárias Ótimas (AMO), formulada por Mundell (1961), parte do pressuposto que o objetivo principal 
da política econômica consiste em manter o equilíbrio externo, sob o argumento de que a mobilidade dos fatores de produção (trabalho e capital) é uma importante questão para determinar o regime cambial ótimo. Mundell (1961) ainda salientou que o limite de uma AMO deve estar associado ao trade-off entre a mobilidade dos fatores de produção e o tamanho da região.

Ao trazer uma nova dinâmica à teoria das AMO, Kenen (1969), além de levar em consideração a mobilidade dos fatores de produção (capital e trabalho), também considerou fundamental a mobilidade dos fatores de produção intraindústria, ou seja, quanto maior a diversificação de uma economia em termos produtivos e capacidade ocupacional, menores são os custos dos choques econômicos.

Conforme Salvatore (1998, p. 377), “essa teoria é de particular interesse por que pode lançar alguma luz sobre o conflito entre a adoção de taxas de câmbio fixas e flexíveis". Outros autores, como McKinnon (1963) e Kenen (1969), também passaram a analisar a idéia de estabelecer uma moeda única para dois ou mais países, admitindo que estes tenham características comuns. Nesse contexto, a área ou bloco, de moeda ótima, é representada por um grupo de nações cujas moedas nacionais se vinculam sob taxas de câmbio permanentemente fixas e a precondições que fazem com que tal área seja considerada ótima. Desse modo, as moedas podem, então, flutuar em conjunto, em relação às moedas das nações não integrantes.

Segundo Krugman e Obstfeld (2005), a integração econômica, baseada em uma AMO com câmbio fixo, pode ter custos que surgem por que um país, que participa de tal integração, abdica da sua capacidade de usar a taxa de câmbio e a política monetária, com o propósito de estimular a produção e o emprego.

Ferrari Filho e De Paula (2002), ao analisarem a obra de McKinnon, enfatizaram que quanto maior e mais aberta a economia de um país, mais eficiente é o sistema de câmbio fixo para restaurar o equilíbrio externo e manter a estabilidade interna.

Outra visão sobre o câmbio fixo, numa AMO foi mencionada por Nunes e Nunes (2000), na qual se verifica que as taxas de câmbio fixas promovem maior disciplina fiscal que as flexíveis. Embora o sistema de bandas seja misto e conjugue virtudes e limitações dos regimes fixos e flexíveis, a determinação da banda, em geral, segue o argumento de que, 
sob taxas de câmbio fixas, a condução de uma política fiscal frouxa geraria problemas de balanço de pagamentos, o que induziria o policy maker à austeridade fiscal, para evitar ruptura nas regras do câmbio e nos custos políticos decorrentes.

Nesse cenário de AMO, Mollo e Silva (1999 p. 200) afirmaram que "a taxa de câmbio não é uma variável de ajuste, mas uma parte da formação das políticas e dos comportamentos financeiros privados que retroagem sobre o conjunto das economias nacionais".

Deve-se destacar que a teoria das Áreas Monetárias Ótimas divide-se em duas abordagens a velha ${ }^{4}$ e a nova teoria ${ }^{5}$. A velha defende que as taxas de câmbio valorizadas são um empecilho para o crescimento, isto porque aumentam o déficit em conta corrente e agravam as desigualdades regionais, dificultando a manutenção da política cambial. Dessa maneira, a união monetária de países, com diferentes estruturas de produção e emprego e sem perfeita mobilidade de mão-de-obra, está sujeita a choques assimétricos. No entanto, a nova visão também faz uma crítica às dificuldades da manutenção da política cambial, mas dá ênfase especial à questão da credibilidade. Para os defensores desta teoria, os formuladores de política econômica deveriam preocupar-se com as diferenças de preferências de níveis de inflação entre os países integrantes que se fazem representar no Banco Central Europeu. Esses autores que defendem esta teoria apregoam a integração e a convergência do orçamento, o que impediria que os governos nacionais realizassem políticas econômicas inflacionárias, bem como leis trabalhistas, para tornar livre o fluxo de mão-de-obra.

\subsection{A fase atual}

Os estados-membros da Comunidade Européia assinaram, em 10 de dezembro de 1991, no Encontro de Cúpula de Maastricht, o Tratado de Maastricht, que foi ratificado oficialmente no ano seguinte. Por este tratado, países com políticas monetárias independentes concordavam em instituir uma união monetária e criar um banco central comum, responsável pela emissão da moeda única e pela política monetária desta união.

Representada por Mundell (1961), Mckinmon (1963), Kenen (1969).

5 Os principais representantes são Barro e Gordon (1983), Giavazzi e Pagano (1988), De Grawe (1996). 
Evidentemente, a opção pela criação de uma moeda única na Europa não surgiu de repente, pois houve alguns antecedentes que motivaram a assinatura do Tratado de Maastricht e, para entendê-los, é preciso conhecer o processo histórico no qual ele foi assinado.

Após a ruptura do sistema de Bretton Woods, intensificou-se a busca da estabilidade cambial na Europa. Já em 1970, foi proposta, por meio do Relatório Werner, uma união monetária neste continente, ao fim de 10 anos. Esse relatório continha propostas detalhadas e prazos estabelecidos para fixação das taxas de câmbio entre as moedas comunitárias, com o objetivo de chegar a uma completa unificação econômica e monetária até 1980. Esse Plano, entretanto, nunca foi posto em prática, devido a uma série de fatores, como a expansão da Comunidade Européia (CE); a grande flutuação das moedas após o colapso do sistema de Bretton Woods; o primeiro choque do petróleo, associado aos desequilíbrios nos balanços de pagamentos; e a manutenção de controles cambiais nos países-membros.

Se a crise do dólar, em 1971, e a primeira crise do petróleo, em 1973, por um lado, ajudaram a impedir o sucesso do Plano Werner, por outro, despertaram o Mercado Comum Europeu para a necessidade de serem criados mecanismos que amortecessem os impactos de crises no mercado mundial. Foi criada, então, uma área monetária, em que se utilizou o sistema conhecido como "serpente européia", que surgiu de um acordo pelo qual a taxa de câmbio dos países participantes só podiam flutuar dentro de estreitos limites. Entretanto, as taxas de câmbio de todas as moedas pertencentes à área monetária poderiam flutuar livremente, em relação ao dólar americano (CORONEL et al., 2005).

As dificuldades na década de 1970, especialmente as ocasionadas pelas crises do petróleo no mercado de euro-dólares, geraram muitas divergências entre os países-membros, mas o interesse comum em defender a estabilidade cambial fez com que os membros da CE se entendessem. Assim, no Conselho Europeu de Bruxelas, em dezembro de 1978, foi criado o Sistema Monetário Europeu (SME), que começou a funcionar em janeiro de 1979. O objetivo principal do SME era estabelecer maior estabilidade monetária na CE e facilitar maior convergência para o desenvolvimento econômico dos países-membros.

Junto ao SME, dentre outras medidas, foram criados a Unidade Monetária Européia (UME) e o Mecanismo de Taxas Cambiais (MTC). A UME é uma cesta de moedas comunitárias, cujo peso de cada uma é estabelecido, 
proporcionalmente, ao tamanho da economia de cada país-membro. Os ajustes necessários eram efetuados a cada cinco anos, ou antes disso, se houvesse desequilíbrio no peso de cada moeda, ocasionado pelo crescimento desigual da economia dos diversos países. O MTC foi utilizado, como unidade de conta e como unidade de reserva, em diversas operações da Comunidade Européia, sendo usado, também, para controlar as variações cambiais entre as moedas comunitárias. As cotações de cada moeda eram fixadas em UME e, a partir delas, fixados os limites bilaterais de variação máxima (WYPLOSZ, 1997).

Em 1986, houve novo impulso para a unificação monetária por meio da assinatura do Ato Único Europeu, que comprometeu os membros da Comunidade Européia com a finalização de um mercado integrado de bens e de fatores até o final de 1992. Apesar do avanço no processo de integração, pode-se dizer que a CE, após quase 30 anos de sua criação, ainda era, em 1985, um mercado mais fragmentado que integrado. Embora algumas políticas comuns tivessem sido adotadas e o mercado de bens e serviços estivesse livre das barreiras tarifárias, o comércio intraregional era atravancado por outros fatores, tais como burocracia aduaneira e divergência de normas sanitárias e de segurança. Além disso, os serviços de fatores estavam sujeitos a uma série de restrições, como o controle de capitais. Esses entraves deixaram de ser exceção e passaram a ser predominantes, e um fator que contribuiu para isso foi a expansão da CE, que incorporou novos países, a maioria dos quais com uma economia de estrutura totalmente diferenciada dos demais.

Para facilitar o processo e aumentar a probabilidade de que o programa de medidas legislativas pudesse ser executado a tempo, foi promulgado, em julho de 1987, o Ato Único Europeu. Para facilitar o processo de tomada de decisão, esse Ato introduziu mudanças na forma de aprovação de decisões em diversas instituições européias, ao substituir a unanimidade pela maioria qualificada.

As medidas implementadas, até o final de 1992, tinham o objetivo de facilitar a livre movimentação de bens, serviços e fatores de produção. Algumas cuidavam de melhorar o acesso aos mercados, retirando os controles de fronteiras intraregional, por exemplo; outras procuravam tornar os mercados mais flexíveis, para que estes funcionassem de forma mais eficiente, harmonizando padrões, certificados de procedência, etc; outras, ainda, visavam 
aumentar a competitividade intra-regional, fiscalizando mais rigorosamente os subsídios governamentais às indústrias e permitindo uma política mais competitiva na prestação de serviços na área da aviação civil.

Em 1988, foi criado um comitê, presidido pelo francês Jacques Delors que propunha estágios concretos rumo à união monetária na Comunidade Européia. O relatório desse Comitê, apresentado no ano seguinte, propôs uma estratégia gradualista para a unificação ${ }^{6}$.

Na disputa entre "monetaristas" e "não monetaristas", o documento pende mais para as posições dos últimos, já que adota o gradualismo nas mudanças propostas, dando tempo para a convergência das estruturas econômicas e das políticas orçamentárias e monetárias dos países-membros. Para isso, foram previstos três estágios, ao final dos quais a CE teria uma só moeda e uma política monetária executada por uma instituição do Sistema Monetário Europeu. Nesse contexto, Goodhart (1996, p.25) mencionou que a unificação monetária poderia propiciar ganhos econômicos: "there is no question in my mind that a single currency does strengthen a single market".

No que tange aos estágios, o primeiro previa um período de grande convergência do desempenho econômico dos países-membros, por meio de um reforço do Sistema de Taxas de Câmbio, do qual todos deveriam participar, e a possível criação de um Fundo de Reserva Europeu (FRE). No início do estágio, ocorreria a retirada de todos os obstáculos aos movimentos de capitais no curto prazo.

No segundo estágio (sem data e sem duração prevista no relatório) seriam estabelecidas estruturas básicas para a união monetária, com a criação do Sistema Europeu de Bancos Centrais (SEBC), cujo objetivo era uma política monetária única para a comunidade.

O terceiro estágio seria caracterizado pela condução final a um regime de taxas de câmbio irrevogavelmente fixas e pela transferência dos poderes de execução da política monetária dos governos nacionais para instituições comunitárias.

A coordenação dessa política pelo comitê dos presidentes dos Bancos Centrais continuava como antes; sem forças para impor qualquer conduta

6 O Relatório Delors, como ficou conhecido, foi preparado por um grupo de "experts", juntamente com os presidentes dos Bancos Centrais dos países-membros da Comunidade Européia, publicado em abril de 1989. Neste relatório são apresentados os objetivos da CE, ou seja, a liberdade total de circulação de pessoas, mercadorias, serviços e capitais e à moeda única. 
aos países-membros, funcionava mais em termos de cooperação entre as partes, já que a transferência de poderes, em termos de política monetária, estava prevista apenas a partir do segundo estágio. A forma como o Relatório foi elaborado permitia a previsão de que cada passo de avanço seria precedido de muitos debates.

A política econômica pós-criação da União Monetária Européia também preocupava (e preocupa até hoje), porque os países-membros teriam um instrumento a menos (Política Monetária) para corrigir seus desequilíbrios internos e ainda teriam a preocupação de não adotar políticas que entrassem em conflito com os objetivos do bloco.

Com o surgimento de mais uma instituição comunitária o Banco Central Europeu, torna-se necessário redefinir o papel das outras instituições e delimitar a área de atuação de cada uma delas. Havia divergências entre França e Alemanha acerca dos poderes do Conselho e do Parlamento sobre as questões da união monetária. A Alemanha, inclusive, propôs o aumento de poder para o Parlamento, em todas as áreas, e redefinição de sua composição, com base no peso populacional de cada país-membro (no caso, ela própria passaria a ter o maior número de parlamentares). Isso, contudo, transcende a questão monetária, mas é possível que esta última tenha contribuído para alguma mudança no papel do Parlamento.

O Tratado de Maastricht mostra a grande capacidade de negociação dos europeus. No final, todos foram atendidos, de uma forma ou de outra. Dessa maneira, o processo de criação da Moeda Única era irreversível; o Euro, que circula desde 2000, já era uma moeda forte mundialmente.

Na Tabela 1, pode-se perceber o efeito da união monetária na Europa, estimando o efeito de uma AMO na região. Observa-se o alto grau de integração dos países, tanto em termos de abertura econômica como em termos comerciais, e as relações comerciais, como porcentagem do PIB dos países, que vão de $43 \%$, no caso da Grécia, a 100\%, no caso da Holanda. No que diz respeito ao percentual em relação ao bloco da União Européia, os países também comercializam em grande medida.

Contudo, o efeito da AMO sobre o PIB per capita é de, no mínimo, $14 \%$ para a Alemanha e de $38 \%$, para a Holanda, país que mais se beneficiou da moeda única, se forem levados em consideração esses critérios de avaliação da AMO européia. 
Tabela 1- Efeito de AMO na União Européia

\begin{tabular}{l|c|c|c}
\hline \multicolumn{3}{c|}{ Exportação e Importação } & PIB per capita \\
\hline & $\begin{array}{c}\text { Total } \\
\text { (\% do PIB) }\end{array}$ & $\begin{array}{c}\text { União Europ. } \\
\text { (cresc. \%) }\end{array}$ & $\begin{array}{c}\text { Efeito da AMO* } \\
\text { (cresc. \%) }\end{array}$ \\
\hline Alemanha & $46 \%$ & $21 \%$ & $14 \%$ \\
\hline Áustria & $78 \%$ & $54 \%$ & $36 \%$ \\
\hline Espanha & $47 \%$ & $29 \%$ & $19 \%$ \\
\hline Finlândia & $68 \%$ & $24 \%$ & $16 \%$ \\
\hline França & $45 \%$ & $25 \%$ & $17 \%$ \\
\hline Grécia & $43 \%$ & $28 \%$ & $18 \%$ \\
\hline Itália & $51 \%$ & $26 \%$ & $17 \%$ \\
\hline Holanda & $100 \%$ & $57 \%$ & $38 \%$ \\
\hline Portugal & $74 \%$ & $50 \%$ & $33 \%$ \\
\hline
\end{tabular}

Fonte: Carneiro (2002).

Para consolidação da União Econômica e Monetária Européia foram necessárias a adequação aos critérios econômicos e fiscais e, sobretudo, a adoção da moeda única ${ }^{7}$ o o respeito à estabilidade dos preços, às finanças públicas, às taxas de juros e às taxas de câmbio (COMISSÃO EUROPÉIA, 2009).

\section{AS EVIDÊNCIAS EMPÍRICAS NAS ÁREAS MONETÁRIAS ÓTIMAS: UNIÃO EUROPÉIA E MERCOSUL}

Nesta seção, faz-se a revisão de vários estudos empíricos sobre as propriedades da Área Monetária Ótima. Os principais benefícios da unificação monetária são: a) aumento da credibilidade da política monetária e redução no viés inflacionário das políticas monetárias nacionais; b) eliminação da incerteza cambial; c) eliminação da incerteza, que diminui as resistências das indústrias domésticas à integração comercial; e d) redução nos custos de transação e de conversão de moedas e das ineficiências a eles associadas (RIGOLON; GIAMBIAGI, 1999).

Euro foi introduzido, inicialmente, para pagamentos oficiais; depois, em transações comerciais e transações eletrônicas do setor bancário. Notas e moedas foram postas em circulação a partir de janeiro de 2002, quando o Euro substituiu o ECU, percursor da moeda única. Para maiores detalhes ver, Giambiagi e Barenboim, 2002. 
Nessa perspectiva, podem-se citar outras propriedades das Áreas Monetárias Ótimas, conforme Mongelli (2002), como o grau de abertura econômica; a diversificação no consumo e na produção; e a similaridade nas taxas de inflação e nos choques.

Frankel e Rose (1996) quantificaram os efeitos de uma unificação monetária, ao utilizarem dados de mais de 200 países, e constataram que a união monetária aumentou o volume comercial dos países-membros.

Dessa forma, apresenta-se uma evidência empírica em favor da hipótese de que os efeitos benéficos de uniões monetárias no desempenho econômico vêm do estímulo ao comércio, e não de outras influências macroeconômicas.

Um estudo realizado por Carneiro (2002), que utilizou os mesmos coeficientes de Frankel e Rose (1996), para medir os efeitos esperados para a adoção de uma moeda única, destacou o efeito de uma AMO sobre os países do Mercosul, conforme demonstra a Tabela 2.

Os efeitos estimados variam de um crescimento mínimo de $2 \%$ sobre o PIB per capita, em 20 anos, para o Brasil, a um crescimento de $10 \%$, para o Paraguai. Pode-se concluir que os benefícios esperados de uma unificação monetária entre os países do Mercado Comum do Sul (MECOSUL) são significativamente limitados. Conforme Ferrari Filho e De Paula (2002), tomando como base a literatura da $\mathrm{AMO}$, uma das precondições para que os países aderissem a uma união monetária dependeria do quanto era integrada ao mercado regional.

Tabela 2: Efeito de uma AMO no Mercosul

\begin{tabular}{c|c|c|c}
\hline \multicolumn{3}{c|}{ Exportação e Importação } & PIB per capita \\
\hline & $\begin{array}{c}\text { Total } \\
(\% \text { do PIB) }\end{array}$ & $\begin{array}{c}\text { Mercosul } \\
\text { (cresc. \%) }\end{array}$ & $\begin{array}{c}\text { Efeito da AMO } \\
\text { (cresc. \%) }\end{array}$ \\
\hline Argentina & $17 \%$ & $5 \%$ & $3 \%$ \\
\hline Brasil & $19 \%$ & $3 \%$ & $2 \%$ \\
\hline Paraguai & $32 \%$ & $15 \%$ & $10 \%$ \\
\hline Uruguai & $27 \%$ & $12 \%$ & $8 \%$ \\
\hline
\end{tabular}

Fonte: Carneiro (2002). 
Nesse sentido, dois fatores poderiam atenuar a necessidade de coordenação de política monetária. O primeiro seria a mobilidade do trabalho e o outro, a criação de um fundo fiscal para a união monetária que transferisse recursos da região em expansão para a região em recessão (CARNEIRO, 2002).

Para o MERCOSUL, a tentativa de uma integração mais coesa deve apresentar os seguintes requisitos propostos por Giambiagi (1999): a) criação de livre comércio; b) harmonização de políticas macroeconômicas; c) valorização taxas de câmbio; d) taxa de inflação de cada país não superior a 3\%; e) diminuição de excessivos déficits fiscais; f) dívida líquida de um país-membro não pode ultrapassar 40\% do PIB; e g) os países não podem apresentar uma relação transações correntes /PIB acima de 3\%.

No que tange aos ônus da criação de uma Área Monetária Ótima para cada uma das regiões isoladas, o principal consiste em abdicar do uso da política monetária e da taxa de câmbio, como instrumentos para responder a distúrbios macroeconômicos ou a outros objetivos. Contudo, caso predominem os choques comuns aos países na área, em relação aos que lhes são específicos, o ônus diminui, porque, do ponto de vista de cada região em particular, torna-se mais provável que a união monetária responda da forma que lhe convém, quando necessitar das políticas monetária e cambial (WYPLOSZ, 1997).

Para Carneiro (2002), faz-se necessário a existência de certo grau de integração produtiva, comercial e financeira prévia à união, pois só assim haverá maior convergência entre os choques.

Segundo Rigolon e Giambiagi (1999), economias mais integradas, com ciclos econômicos simétricos, alta mobilidade do trabalho e convergência de indicadores macroeconômicos relevantes, teriam mais a ganhar com a formação de uma área monetária e, portanto, teriam maiores chances de êxito com uma AMO.

Ao visualizar uma integração continental, Giambiagi (1999) afirmou que se o Mercosul limitasse apenas a ser um Mercado Comum, com uma tarifa externa comum, sua força seria relativamente diminuída, caso viesse a constituir a Área de Livre Comércio das Américas (ALCA), já que desapareceriam as tarifas no interior do conjunto da América do Norte, Central e do Sul, o que acarretaria uma perda de poder de diferenciação da sub-região em relação aos demais países do continente. 
Conforme Giambiagi (1999), a eventual unificação monetária poderia trazer os seguintes benefícios para o Mercosul's: a) a transformação da região em uma plataforma de exportação para terceiros países; b) redução dos riscos; c) a queda das taxas de juros; e e) o estímulo a novos investimentos.

A moeda comum é o último passo, num processo de integração, e só poderia ser adotada após maior integração dos países, eliminando, dessa forma, as listas de exceções à Tarifa Externa Comum (TEC), a harmonização das legislações nos campos trabalhista, tributário e de mercado de capitais, e a integração dos sistemas financeiros, pois sem o cumprimento desses requisitos, não haveria as condições de adoção de uma moeda única (GIAMBIAGI, 1998).

O futuro do Mercosul ainda é muito dependente de condições macroeconômicas dos países que compõem o bloco, pois a harmonização da estrutura tributária, a coordenação de políticas cambiais, a busca de interesses comuns e a atuação conjunta nas negociações para formação da ALCA e de um acordo com a União Européia são desafios a serem vencidos e que têm impactos significativos nos setores produtivos.

As lições da experiência européia parecem não ter sido assimiladas pelos parceiros do Mercosul. O que se observa, apesar de uma tentativa de formalmente imitar uma sequência temporal de passos de integração comercial, foi exatamente uma desorganização da coordenação macroeconômica. Por exemplo, o Brasil encontrou um caminho próprio adequado aos seus interesses a partir de 1999, com a flutuação do câmbio, mas os seus parceiros foram penalizados por essa política (MORAES, 2001).

De acordo com Guelar (2001), se no início do processo de formação do MERCOSUL houvesse um princípio de um leque cambial claramente estabelecido, algo semelhante à serpente cambial adotada na Europa, possivelmente teria havido uma aproximação dos programas macroeconômicos, evitando, dessa forma, os processos transformados em desvalorização, e ter-se-ia um instrumento de liquidação do déficit interno.

Para Carneiro (2002), os critérios que definem uma região como AMO são subjetivos, e a evidência empírica não implica, necessariamente, que não valha a pena para o Brasil, Uruguai, Argentina e Paraguai compartilharem

Para verificar uma série de outras vantagens em relação a uma AMO no Mercosul, sobretudo para Brasil e Argentina, ver Giambiagi e Barenboim (2002, p3I). 
de uma moeda comum, apenas ilustra que a relação custo/beneficio das políticas coordenadas será superior à dos países da União Européia.

Com base na discussão sobre as dificuldades de implantar uma moeda única, Bonelli e Hahn (2000) salientaram que o MERCOSUL está muito distante de alcançar uma união monetária, pois, para chegar a uma moeda única no bloco, seria necessário que as taxas de câmbio fossem fixas entre os quatro países que o integram, decisão esta que dependeria de uma condição prévia, qual seja, a estabilidade econômica com equilíbrio fiscal.

Apesar dessas tendências desfavoráveis à integração regional no curto prazo, é importante que o esforço despendido não seja em vão. Porém, para retomar o processo no marco do MERCOSUL, será necessário um comprometimento muito mais forte na área de coordenação macroeconômica. Isso significa que o Brasil e a Argentina, bem como ou outros membros do bloco, devem, de algum modo, resolver o impasse cambial e monetário ora existente e acertar um mecanismo institucional que mantenha a consistência mútua de suas políticas.

\section{CONCLUSÕES}

Neste trabalho, realizou-se uma revisão de literatura sobre as Áreas Monetárias Ótimas, mostrando o que há na literatura recente sobre o assunto e destacando, principalmente, as etapas para implementação de uma AMO, os resultados empíricos e a possibilidade de aplicação desta teoria no MERCOSUL.

No caso da AMO para o Mercosul, constata-se ainda que há poucas perspectivas de implantação devido não só aos grandes desníveis entre os países, mas, sobretudo, pela falta de coordenação de políticas econômicas.

Nesse contexto, espera-se que as intrínsecas concepções estabelecidas na economia internacional se mantenham e que as políticas econômicas das nações ainda sejam direcionadas para evitar as consequências dos desequilíbrios externos que estão cada vez mais presentes, em razão da falta de uma nova ordem mundial que limite e estabeleça regras para o comportamento das variáveis macroeconômicas, como a taxa de câmbio, que tanto influencia este cenário.

Por isso, entende-se que a formação de AMO foi uma saída encontrada pela União Européia para viabilizar seu desempenho econômico e possibilitar 
maior coesão social e, dessa forma, dar maior sustentabilidade ao bloco, além de propiciar ampliação de suas fronteiras por meio de critérios bem definidos.

No entanto, apesar de constatar que os países do Mercosul apresentam índices macroeconômicos de convergência muito díspares, os membros do bloco devem apostar numa união monetária, resolvendo, antes, outros pontos de coordenação mais simples. Dessa maneira, uma implantação de AMO poderia assegurar maior integração ao bloco e, aos poucos, desenvolver uma coordenação macroeconômica e dar credibilidade diante do cenário internacional.

Por fim, pode-se dizer que a perspectiva de uma AMO no Mercosul indica que o bloco tenderá a receber os benefícios de uma união monetária, em decorrência do estímulo ao comércio, mas, em contrapartida, a autonomia dos países, no momento de utilizar as medidas de política monetária e cambial, ficará comprometida com os objetivos supranacionais.

\title{
OPTIMAL CURRENCY AREAS: RECENT DEVELOPMENTS AND PERSPECTIVES FOR MERCOSUR MEMBERS
}

\begin{abstract}
This paper consists of a review of the most important contributions to the understanding of the Optimum Currency Areas (OMA) and of the perspective of implementing such a policy measure into Mercosur. The theoretical support was obtained from reference studies on the European common currency which established the guidelines for the creation of the Euro zone. The findings on the literature review point out that a successful process of macroeconomic coordination is crucial for the implementation of a common currency area. Therefore, before engaging in a process of establishing a common currency area, Mercosur's members must adopt supranational macroeconomic policy measures that would align their economies to reach stabilization in a regional context.
\end{abstract}

Keywords: Otimum Currency Areas; Macroeconomic Coordination; Mercosur 


\section{REFERÊNCIAS BIBLIOGRÁFICAS}

BARRO, R. J; GORDON, D. Rules, discretion and reputation in a model of monetary policy. Journal of Monetary Economics, v. 12, p. 101-121, 1983.

BONELLI, R.; HAHN, L. Resenha dos Estudos. Recentes sobre Relações Comerciais. Brasileiras. Rio Janeiro: IPEA, 2000. (Texto para discussão n. 708).

CARNEIRO, D. D. Sobre a unificação monetária no Mercosul. Carta Economica Galanto. n. 27, 2002.

COMISSÃO EUROPÉIA. A política fiscal na União Européia. Luxemburgo: Serviço das publicações oficiais das comunidades européias, 2009.

CORONEL, D. A. et al. Perspectiva de Uma União Monetária no Mercosul. Revista Cenários Regionais, Santa Maria, v.2, p. 01-15, 2005.

DE GRAWE, P. Monetary union and convergence of economics. European Economic Review, n.40, p.156-176, 1996.

DUTRA, D. C. Análise do Comportamento e evolução das taxas de câmbio do Brasil e da Argentina e a possibilidade de maior convergência para o Mercosul. 2003. Dissertação (Mestrado em Integração LatinoAmericana). Universidade Federal de Santa Maria, Santa Maria, 2003.

FERRARI FILHO, F; DE PAULA, L. F. Será consistente a proposta de criação de uma União Monetária no Mercosul. Economia Política, São Paulo, v. 22, n. 2, p. 174-182, 2002.

FRANKEL, J. A.; ROSE, A. K. The endogeneity of the optimum currency area criteria. NBER Working Paper, n.5700, 1996.

GIAMBIAGI, F. Mercosul Por que a unificação monetária faz sentido a longo prazo? Brasil, 1999 Disponível em: <http//www.bndes.gov.br>. Acesso em: 20 de set, 2009. 
GIAMBIAGI, F. Moeda única do Mercosul: notas para o debate. Revista Brasileira de Política Internacional, Brasília, v.41, n.1, p.24-39, 1998.

GIAMBIAGI, F.; BARENBOIM, I. A unificação monetária alemã: lições para uma possível moeda comum entre Brasil e Argentina. Revista do BNDES, Rio de Janeiro, v. 9, n. 18, p. 85-120, 2002.

GIAVAZZI, F; PAGANO, M. The advantage of tying one's hands: EMS discipline and Central Bank credibility. European Economic Review, n.32, n. 5, p.120-132, 1988.

GOODHART, C. A. E. European Economic integration. European Economic Review, v.40, n.3, p.120-140, 1996

GUELAR, Diego. Argentina e Brasil necessitam mercosulizar políticas. 2001 Disponível em <http//www.mercosul.br > . Acesso em: 20 de ago, 2009.

KENEN, P. The theory of optimum currency areas: an eclectic view. In: MUNDELL, R.; SWOBODA, A. (Eds). Monetary problems of the international economy.Chicago: University of Chicago Press, p. 41-60, 1969.

KRUGMAN, P. R; OBSTFELD, M. Economia Internacional: teoria e política. 6. ed. São Paulo: Pearson Addison Wesley, 2005.

MCKINNON, R. I. Optimum currency areas. American Economic Review, v. 53, n.4 p.717-25, 1963.

MOLLO, M. L. R.; PONTES, F. P. A Liberalização do Câmbio no Brasil: Revisitando a discussão dos pressupostos teóricos embutidos nas prescrições cambiais alternativas. Estudos Econômicos. São Paulo, v. 29, n. 2, p. 189-227, 1999.

MONGELLI, F. P. News views on the optimum currency areas theory: what is EMU telling us? European Central Bank. Working Papers Series, $\mathrm{n}^{\mathrm{o}} 138,2002$. 
MORAES, R. C. O Brasil e a ALCA. Indicadores Econômicos, Porto Alegre: FEE, v. 29, n. 3, p. 51-69, 2001.

MUNDELL, R. A Theory of Optimum Currency Areas. American Economic Review ,vol. 51,n.3, p. 657-665,1961.

NUNES, R.; NUNES, S. União Monetaria Européia: Evolução recente e perspectivas. Revista de Economia Política, São Paulo, vol. 20, n. 1, p.51-71, 2000.

RIGOLON, F.; GIAMBIAGI, F. Áreas monetárias ótimas: teoria, unificação monetária européia e aplicação para o Mercosul. Economia Aplicada, São Paulo, v. 03, n. 1, p. 79-99 jan.-mar. 1999.

SALVATORE, D. Economia Internacional. 6. ed. Rio de Janeiro: LTC, 1998.

WYPLOSZ, C. EMU: why and how it might happen. Journal of Economic Perspectives, v.11, n.4, p.220-240, 1997. 